\title{
Comparative analysis of apoptotic changes in peripheral immune organs and lungs following experimental infection of piglets with highly pathogenic and classical porcine reproductive and respiratory syndrome virus
}

Gang Wang ${ }^{1}$, Yuli He${ }^{1}$, Yabin Tu ${ }^{1}$ Yonggang Liu', En-Min Zhou², Zifeng Han ${ }^{1,3}$, Chenggang Jiang ${ }^{1}$, Shujie Wang ${ }^{1}$, Wenda Shi ${ }^{1}$ and Xuehui Cai ${ }^{{ }^{*}}$

\begin{abstract}
Background: Our previous studies have demonstrated that piglets infected with highly pathogenic porcine reproductive and respiratory syndrome virus (HP-PRRSV) may develop significant thymus atrophy, which related to thymocytes apoptosis. However, apart from that detected in the thymus, there are no reports describing cell apoptosis induced by HP-PRRSV infection. In this study, we analyzed comparatively the pathological changes, cell apoptosis and viral load in peripheral immune organs including tonsil, inguinal lymph nodes (ILNS) and spleen and lungs following experimental infection of piglets with HP-PRRSV HuN4 and classical PRRSV CH-1a.

Findings: HP-PRRSV HuN4 exhibited much stronger cell tropism than $\mathrm{CH}-1$ a in immune organs and lungs of piglets. HuN4 infection led to the serious injuries in tonsils, ILNs, spleens and lungs, especially apoptosis in these organs was significant.

Conclusions: HuN4 infection induced severe lesions (gross pathology, histopathology and cell apoptosis) in the peripheral immune organs and lungs of infected piglets. Large numbers of apoptotic cells in immune organs and lung induced by HuN4 may play a role in the pathogenesis of the HP-PRRS and the distinct injuries caused by HuN4 infection may be associated with the high mortality rate of HP-PRRS in pigs.
\end{abstract}

Keywords: Highly pathogenic PRRSV, Classical PRRSV, Peripheral immune organs, Lung, Cell apoptosis

\section{Findings}

\section{Summary and experimental design}

Porcine reproductive and respiratory syndrome (PRRS) was first recognized in the United States and Europe in 1987 and 1990, respectively [1-4]. Highly pathogenic PRRS (HP-PRRS) first emerged in China and Vietnam in 2006, and then spread rapidly in pigs throughout Asia [5,6]. Classical PRRSV infection induces apoptosis in different organs (lungs, testes, lymph nodes and thymus) in

\footnotetext{
* Correspondence: cai139@hvri.ac.cn

'State Key Laboratory of Veterinary Biotechnology, Harbin Veterinary Research Institute, Chinese Academy of Agricultural Sciences, Harbin, Heilongjiang Province 150001, PR China

Full list of author information is available at the end of the article
}

vivo and in cell lines in vitro [7-10], with apoptosis observed in both PRRSV-positive and PRRSV-negative cells $[9,11]$. However, apart from that detected in the thymus, there are no reports describing cell apoptosis induced by HP-PRRSV infection.

PRRSV CH-1a (GenBank accession no. EU807840) and HuN4 (GenBank accession no. EF635006) represent the classical and highly pathogenic PRRSV strains, respectively. Our previous studies have demonstrated that piglets infected with the HuN4 strain developed significant thymus atrophy, which was related to cell apoptosis; however, piglets infected with the $\mathrm{CH}-1$ a strain showed mild pathological lesions and a few apoptotic cells in the thymus $[12,13]$. In this study, we sought to clarify the role of

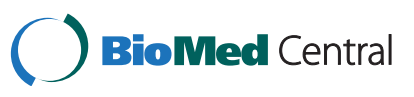


apoptosis in lesions of the peripheral immune organs and lungs of piglets experimentally infected with either the highly pathogenic (HuN4) or the classical $(\mathrm{CH}-1 \mathrm{a})$ virulence strains of PRRSV. The experimental design has been described in previously published study [13]. Briefly, three groups (15 piglets/group) were used in this study, Group 1 and Group 2 piglets were inoculated with $2 \mathrm{ml}$ of $\mathrm{HuN} 4$ and $\mathrm{CH}-1 \mathrm{a}\left(7.9 \times 10^{5} \mathrm{TCID}_{50}\right.$ in $2 \mathrm{ml}$ DMEM medium), respectively. Group 3 were sham-inoculated with $2 \mathrm{ml}$ of DMEM medium. Three piglets from each group were humanely euthanized at 0 day post-inoculation (DPI), 3 DPI, 7 DPI, 10 DPI and14 DPI, respectively. In present study, we utilized the tonsils, inguinal lymph nodes (ILNs), spleens and lungs of piglets from the published study and this study is an extension of that study.

\section{Gross pathology}

The gross pathological changes of peripheral immune organs and lungs were recorded during necropsy. In Group 1, the lesions in tonsil, ILNs and spleen were characterized by swelling or diffuse hemorrhage, which were the same to our previous reported [12], and the lungs showed red and beige variegated appearance from 7 DPI [14]. In Group 2, the main lesions were found in the ILNs and lungs and were characterized by swelling in the ILNs and mild interstitial pneumonia in the lungs. In Group 3 piglets, the organs investigated remained normal throughout the experiment and no lesions were detected.

\section{Detection of virus in tissues}

Real-time RT-PCR quantitation (qRT-PCR) of viral loads in peripheral immune organs and lungs was performed as previously described [14]. In Group 1, high titers of PRRSV were detected in tonsils, ILNs, spleen and lungs of three piglets from 3 DPI to the end of the experiment (approximately $10^{8}$ copies $/ g$ ), which were similar to those observed in previous study [12]. In Group 2, PRRSV was also detected in tonsils, ILNs, spleen and lungs of piglets euthanized at 3 DPI. However, the viral loads were low (approximately $10^{5}$ copies/g) and were maintained at low viral loads to 14 DPI. No viruses were detected in any of the tissues investigated from Groups 1 and 2 euthanized at 0 DPI or from Group 3 piglets euthanized at any of the time-points during the experiment.

\section{Histopathologic examination}

Tissue samples of the tonsil, ILNs, spleen and lungs collected on different DPI were used for histological examination using hematoxylin and eosin (H\&E) staining as described previously [15]. Tonsils, ILNs and spleens were evaluated for the presence of lymphoid depletion ranging from 0 (normal) to 3 (severe) and inflammation and replacement of follicles ranging from 0 (normal) to 3 (severe) according to the established scoring system [16-18].
Lung sections were scored for the presence and severity of interstitial pneumonia ranging from 0 (no microscopic lesions) to 4 (severe interstitial pneumonia) as described previously [19]. In Group 1, lymphoid depletion, inflammation and replacement of follicles of tonsils, ILNs and spleens appeared at $3 \mathrm{DPI}$, and became more severe at $7 \mathrm{DPI}$; severe interstitial pneumonia of the lungs were observed at 10 DPI (Table 1). In Group 2, lymphoid depletion, inflammation and replacement of follicles and interstitial pneumonia were mild throughout the experiment.

\section{Cell apoptosis detection}

Apoptotic cells were detected in tonsils, ILNs, spleen and lungs using the TUNEL technique as previously reported [20] with the In Situ Cell Death Detection Kit (Roche, Mannheim, Germany) according to the manufacturer's instructions. The number of labeled cells per unit area $\left(\mathrm{mm}^{2}\right)$ was calculated and the results were expressed as mean \pm standard deviation. Evaluation of apoptotic thymocytes was conducted as our previously described [13]. Statistical analyses were performed using GraphPad PRISM software for analysis of variance (ANOVA), and the $P$-value $<0.05$ was considered statistical significance.

In Group 1, TUNEL-positive cells were observed in tonsils at 3 DPI and peaked at 10 DPI, and most of the apoptotic cells were observed in lymphatic nodules (Figure 1A and $\mathrm{B}$ ), the similar results were observed in ILNs and spleen. In Group 2, TUNEL-positive cells were also observed during the experiment although, at lower frequencies than that of Group 1 at 3,7 and 10 DPI $(P<0.05)$ (Table 2).

The number of TUNEL-positive cells in the lungs of Group 1 was approximately 9 cells per $\mathrm{mm}^{2}$ from 3 to 10 DPI (Figure 2), and the apoptotic cells included the porcine alveolar macrophages (PAMs) and type II pneumocytes (Figure 2A and B). In Group 2, this number increased from 3 to 6 cells per $\mathrm{mm}^{2}$ during the period from 3 to 14 DPI, type II pneumocytes and macrophages (Figure 2C and D) were also observed undergoing apoptosis. A significant difference in the number of apoptotic cells among groups was detected at 3, 7 and 10 DPI $(P<0.05)$ (Table 2).

\section{Discussion}

HP-PRRSV infection induces higher rates of morbidity and mortality in animals of different ages than PRRSV infection $[5,6,21,22]$. However, differences in the lesions on peripheral immune organs and lungs following experimental infection of pigs with highly pathogenic and classical PRRSV have not yet to be reported. In this study, higher viral loads were detected in peripheral immune organs (tonsils, ILNs, spleens) and lungs of piglets infected with the HP-PRRSV HuN4 strain than that of pigs infected with the classical PRRSV CH-1a strain. Viral replication in 
Table 1 Histopathological changes of immune organs and lungs at different days post-inoculation (DPI)

\begin{tabular}{|c|c|c|c|c|c|c|c|c|}
\hline \multirow[t]{3}{*}{ Group } & \multirow[t]{3}{*}{$\mathrm{DPI}^{*}$} & \multicolumn{7}{|c|}{ Histological lesion score ${ }^{\#}$ (No. of piglets with lesions/no. of piglets examined) } \\
\hline & & \multicolumn{2}{|c|}{ Tonsil } & \multicolumn{2}{|c|}{ ILN } & \multicolumn{2}{|c|}{ Spleen } & \multirow{2}{*}{$\begin{array}{l}\text { Lung } \\
\text { c }\end{array}$} \\
\hline & & $\mathrm{a}$ & b & a & b & $\mathrm{a}$ & b & \\
\hline \multirow[t]{5}{*}{1} & 0 & 0 & 0 & 0 & 0 & 0 & 0 & 0 \\
\hline & 3 & $1(1 / 3)$ & 0 & $1(2 / 3)$ & $1(1 / 3)$ & $1(2 / 3)$ & 0 & $1(1 / 3)$ \\
\hline & 7 & $2(3 / 3)$ & $1(1 / 3)$ & $1.5(2 / 3)$ & $1(2 / 3)$ & $1(2 / 3)$ & $1.5(2 / 3)$ & $1(2 / 3)$ \\
\hline & 10 & $3(3 / 3)$ & $2.7(3 / 3)$ & $1.7(3 / 3)$ & $1.7(3 / 3)$ & $2(3 / 3)$ & $2(2 / 3)$ & $3(3 / 3)$ \\
\hline & 14 & $3(3 / 3)$ & $3(3 / 3)$ & $3(3 / 3)$ & $2(3 / 3)$ & $3(3 / 3)$ & $2(3 / 3)$ & $4(3 / 3)$ \\
\hline \multirow[t]{5}{*}{2} & 0 & 0 & 0 & 0 & 0 & 0 & 0 & 0 \\
\hline & 3 & 0 & 0 & 0 & 0 & 0 & 0 & 0 \\
\hline & 7 & $2(1 / 3)$ & 0 & $1(2 / 3)$ & 0 & 0 & $1(1 / 3)$ & $1(1 / 3)$ \\
\hline & 10 & $2(2 / 3)$ & $1.3(3 / 3)$ & $1(2 / 3)$ & 0 & $1(2 / 3)$ & 0 & $1.3(3 / 3)$ \\
\hline & 14 & $1(1 / 3)$ & $1(2 / 3)$ & $1(2 / 3)$ & $1(2 / 3)$ & $1(2 / 3)$ & $1.5(2 / 3)$ & $1.3(2 / 3)$ \\
\hline
\end{tabular}

\footnotetext{
* Days post-inoculation when pigs were necropsied.

\# Mean histological lesion score of piglets with lesions.

a Histological lymphoid depletion score: 0 , normal; 1 , mild; 2 , moderate; 3 , severe.

b Inflammation and replacement of follicles score: 0 , normal; 1 , mild; 2 , moderate; 3 , severe.

c Interstitial pneumonia score: 0 , no microscopic lesions; 1, mild interstitial pneumonia; 2, moderate multifocal interstitial pneumonia; 3 , moderate diffuse interstitial pneumonia; 4 , severe interstitial pneumonia.
}

these organs leads to the serious lesions (Table 1). Depletion of peripheral immune organs adversely affects the capacity for eradication of viruses and bacteria, and immunity to endogenous and exogenous substances with a variety of specific morphological and functional consequences. HuN4 infection causes severe immunosuppression and enhances susceptibility to secondary infections and also induces severe thymic atrophy [13]. The severe damage to immune organs and lungs mediated by HuN4 may cause the high mortality rate associated with HP-PRRS in pigs.

Besides the apoptosis observed in thymocytes [13], significant numbers of apoptotic cells were also observed

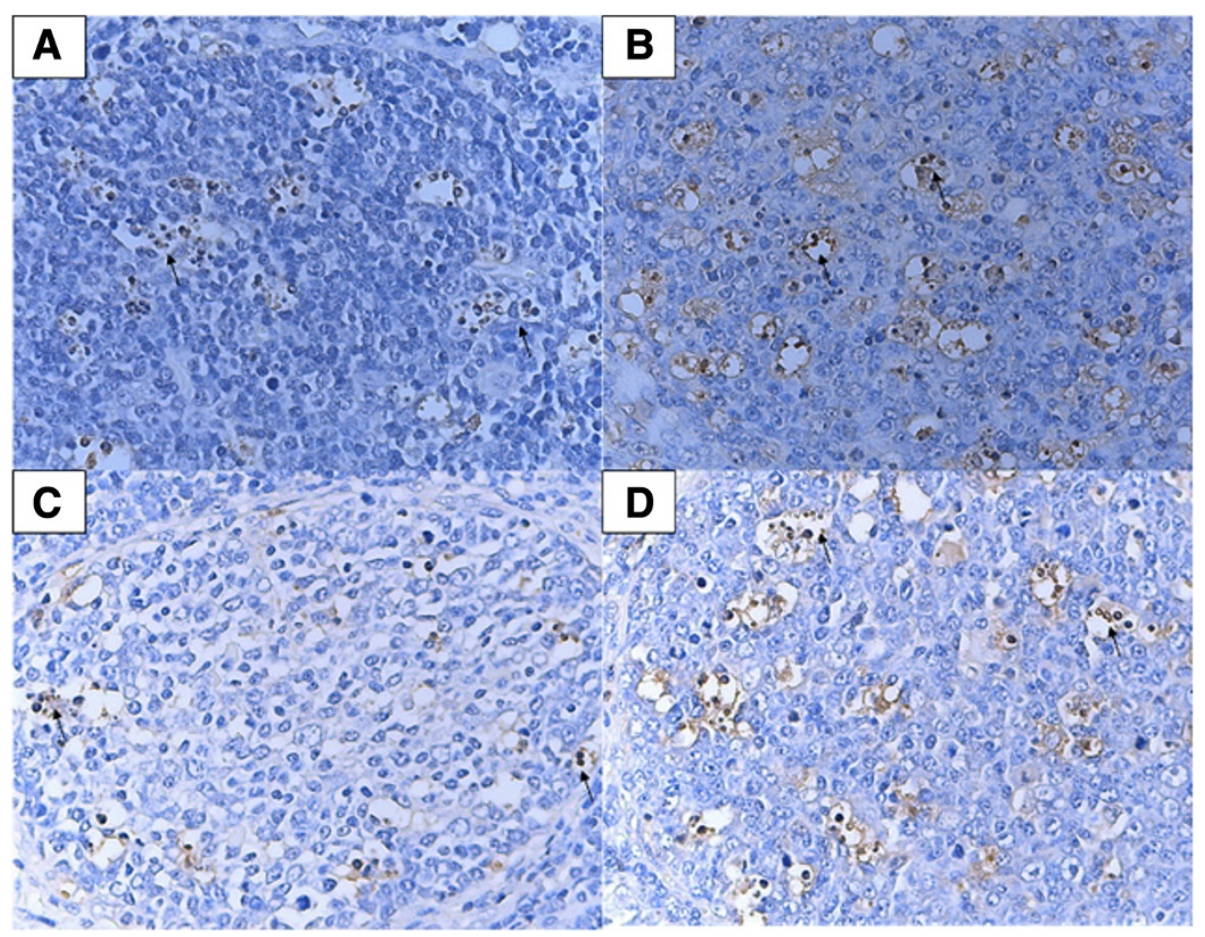

Figure 1 TUNEL assay with tonsil tissues of piglets during infection. Shown are tonsil tissue sections from HuN4 strain-infected piglets at 3 DPI (A) and 10 DPI (B) and from CH-1a strain-infected piglets at 3 DPI (C) and 10 DPI (D), respectively. The arrows denote areas of TUNEL-positive cells. Cells undergoing apoptosis were mainly lymphocytes. 
Table 2 The number of apoptotic cells in immune organs and lungs at different days post-infection (DPI)

\begin{tabular}{|c|c|c|c|c|c|c|c|c|c|c|c|c|}
\hline \multirow[t]{3}{*}{$\mathrm{DPI}^{*}$} & \multicolumn{12}{|c|}{ The number of apoptotic cells (per $\mathrm{mm}^{2}$ ) } \\
\hline & \multicolumn{3}{|c|}{ Tonsil } & \multicolumn{3}{|c|}{ ILN } & \multicolumn{3}{|c|}{ Spleen } & \multicolumn{3}{|c|}{ Lung } \\
\hline & 1 & 2 & 3 & 1 & 2 & 3 & 1 & 2 & 3 & 1 & 2 & 3 \\
\hline 0 & $0.4 \pm 0.2$ & $0.5 \pm 0.2$ & $0.4 \pm 0.2$ & $0.4 \pm 0.2$ & $0.3 \pm 0.2$ & $0.4 \pm 0.2$ & $0.4 \pm 0.2$ & $0.2 \pm 0.1$ & $0.3 \pm 0.2$ & $0.4 \pm 0.2$ & $0.4 \pm 0.2$ & $0.3 \pm 0.2$ \\
\hline 3 & $17.7 \pm 0.9^{a}$ & $5.0 \pm 0.7^{b}$ & $0.3 \pm 0.2^{c}$ & $18.3 \pm 0.8^{a}$ & $6.3 \pm 0.5^{b}$ & $0.4 \pm 0.2^{c}$ & $8.1 \pm 0.5^{a}$ & $4.3 \pm 0.5^{b}$ & $0.4 \pm 0.2^{c}$ & $8.2 \pm 0.8^{\mathrm{a}}$ & $2.8 \pm 0.5^{b}$ & $0.4 \pm 0.2^{c}$ \\
\hline 7 & $20.0 \pm 0.8^{a}$ & $7.7 \pm 0.4^{b}$ & $0.4 \pm 0.2^{c}$ & $21.5 \pm 0.6^{a}$ & $9.0 \pm 0.5^{b}$ & $0.4 \pm 0.2^{c}$ & $13.0 \pm 0.8^{\mathrm{a}}$ & $7.3 \pm 0.4^{b}$ & $0.4 \pm 0.2^{c}$ & $8.7 \pm 0.7^{\mathrm{a}}$ & $4.4 \pm 0.6^{b}$ & $0.4 \pm 0.2^{c}$ \\
\hline 10 & $21.9 \pm 1.4^{\mathrm{a}}$ & $11.0 \pm 0.8^{b}$ & $0.5 \pm 0.2^{c}$ & $23.8 \pm 0.8^{a}$ & $13.6 \pm 0.5^{b}$ & $0.4 \pm 0.2^{c}$ & $19.4 \pm 0.9^{a}$ & $9.5 \pm 0.4^{b}$ & $0.5 \pm 0.2^{c}$ & $9.0 \pm 0.4^{a}$ & $5.6 \pm 0.6^{b}$ & $0.4 \pm 0.2^{c}$ \\
\hline 14 & $14.8 \pm 0.8^{a}$ & $12.6 \pm 0.8^{a}$ & $0.2 \pm 0.1^{b}$ & $14.2 \pm 0.8^{\mathrm{a}}$ & $10.4 \pm 0.7^{b}$ & $0.4 \pm 0.2^{c}$ & $14.2 \pm 0.6^{\mathrm{a}}$ & $13.9 \pm 0.8^{a}$ & $0.4 \pm 0.2^{b}$ & $6.8 \pm 0.5^{a}$ & $6.1 \pm 0.4^{a}$ & $0.3 \pm 0.2^{b}$ \\
\hline
\end{tabular}

*Days post-inoculation when pigs were necropsied.

$a, b, c$ Values with different superscripts indicate mean value score differences among groups $(P<0.05)$.

in tonsils, ILNs, spleen and lungs of piglets infected with HuN4 (Table 2). However, few apoptotic cells were detected in these tissues of piglets infected with $\mathrm{CH}-1 \mathrm{a}$, which was consistent with the results of previous studies of cell apoptosis induced by classical PRRSV infection $[10,23,24]$. Large numbers of apoptotic cells in these organs induced by HuN4 infection indicated that apoptosis may play a role in the pathogenesis of the HP-PRRS, with increased apoptotic cells associated both with more severe tissue injury and with increased viral loads. Moreover, more apoptotic cells were observed in immune organs of HP-PRRSV infected piglets pointing out a mechanism which might play a role in the induction of the erratic host immune response observed in HP-PRRSV infected pigs [14]. The apoptotic cells, along with the subsequent microscopical and gross lesions may trigger events that immune balance and induce immunosuppression. However, a specific association between cell apoptosis and PRRSV infection requires further investigation.

In conclusion, this is the first report describing a comparative investigation of apoptotic cells in peripheral immune organs and lungs of piglets following experimental infection with the highly pathogenic and classical PRRSV strains. Large numbers of apoptotic cells in immune organs and lung induced by HuN4 infection may play a role in the pathogenesis of the HP-PRRS.

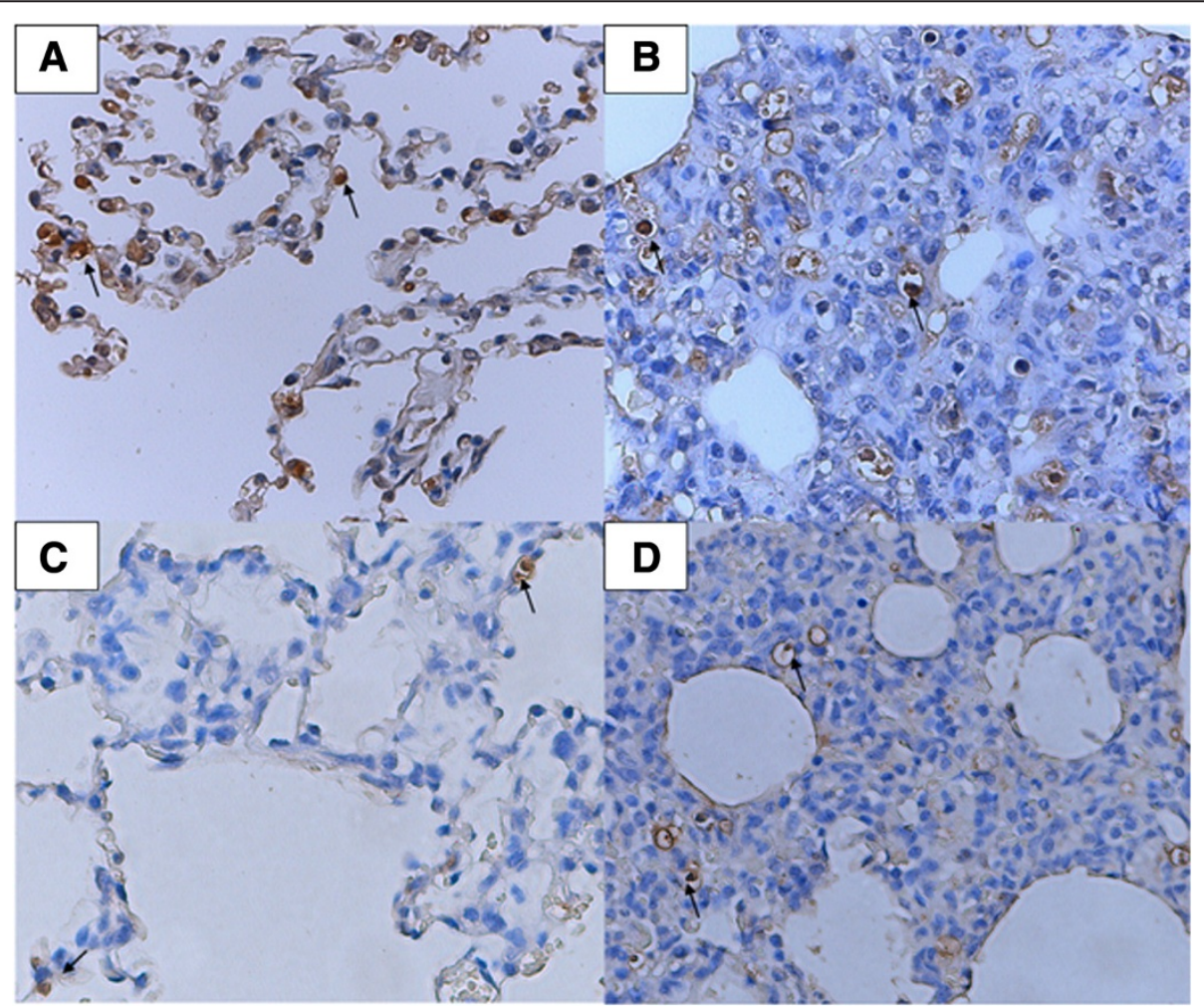

Figure 2 TUNEL assay with lung tissues of piglet during infection. Shown are lung tissue sections from HuN4 strain-infected piglets at 3 DPI (A) and 10 DPI (B) and from $\mathrm{CH}$-1a strain-infected piglets at 3 DPI (C) and 10 DPI (D), respectively. The arrows in $\mathbf{A}$ and $\mathbf{C}$ show cells undergoing apoptosis were type II pneumocytes, and in $\mathbf{B}$ and $\mathbf{D}$ were macrophages. 


\section{Competing interests}

The authors declare that they have no competing interests.

\section{Authors' contributions}

Conceived and designed the experiments: $\mathrm{CXH}$ and WG; Performed the experiments: WG, HYL, LYG, HZF, JCG, WSJ and SWD. Critical discussion and final approval of manuscript: WG, HYL, TYB, LYG, ZEM, HZF, JCG, WSJ, SWD, $\mathrm{CXH}$. All authors approved the final manuscript.

\section{Acknowledgements}

This work was supported by grants from the National Natural Science Foundation for Young Scholars of China (31201885), the Science and Technology Research Project of Harbin (2010AA6AN083) and the Fundamental Research Funds of Chinese Academy of Agricultural Sciences (2012ZL079/SKLVBP201317-5).

\section{Author details}

'State Key Laboratory of Veterinary Biotechnology, Harbin Veterinary Research Institute, Chinese Academy of Agricultural Sciences, Harbin, Heilongjiang Province 150001, PR China. ${ }^{2}$ Department of Preventive Veterinary Medicine, College of Veterinary Medicine, Northwest A\&F University, Yangling, Shaanxi 712100, PR China. ${ }^{3}$ Northeast Agricultural University, Harbin 150030, PR China.

Received: 4 July 2013 Accepted: 3 January 2014

Published: 6 January 2014

\section{References}

1. Wensvoort G, Terpstra C, Pol JM, ter Laak EA, Bloemraad M, de Kluyver EP, Kragten C, van Buiten L, den Besten A, Wagenaar F, et al: Mystery swine disease in The Netherlands: the isolation of Lelystad virus. Vet Q 1991 13:121-130.

2. Terpstra C, Wensvoort G, Pol JM: Experimental reproduction of porcine epidemic abortion and respiratory syndrome (mystery swine disease) by infection with Lelystad virus: Koch's postulates fulfilled. Vet Q 1991, 13:131-136.

3. Collins JE, Benfield DA, Christianson WT, Harris L, Hennings JC, Shaw DP, Goyal SM, McCullough S, Morrison RB, Joo HS: Isolation of swine infertility and respiratory syndrome virus (isolate ATCC VR-2332) in North America and experimental reproduction of the disease in gnotobiotic pigs. J Vet Diagn Invest 1992, 4:117.

4. Rossow KD: Porcine reproductive and respiratory syndrome. Vet Pathol 1998, 35:1-20

5. Tian K, Yu X, Zhao T, Feng Y, Cao Z, Wang C, Hu Y, Chen X, Hu D, Tian X, et al: Emergence of fatal PRRSV variants: unparalleled outbreaks of atypical PRRS in China and molecular dissection of the unique hallmark PLoS One 2007, 2:e526.

6. Dukic S, Heurtaux T, Kaltenbach ML, Hoizey G, Lallemand A, Gourdier B, Vistelle R: Pharmacokinetics of methotrexate in the extracellular fluid of brain C6-glioma after intravenous infusion in rats. Pharm Res 1999, 16:1219-1225

7. Feng WH, Tompkins MB, Xu JS, Brown TT, Laster SM, Zhang HX, McCaw MB: Thymocyte and peripheral blood T lymphocyte subpopulation changes in piglets following in utero infection with porcine reproductive and respiratory syndrome virus. Virology 2002, 302:363-372.

8. Labarque G, Van Gucht S, Nauwynck H, Van Reeth K, Pensaert M: Apoptosis in the lungs of pigs infected with porcine reproductive and respiratory syndrome virus and associations with the production of apoptogenic cytokines. Vet Res 2003, 34:249-260.

9. Sur $\mathrm{JH}$, Doster AR, Osorio FA: Apoptosis induced in vivo during acute infection by porcine reproductive and respiratory syndrome virus. Vet Pathol 1998, 35:506-514.

10. Sur JH, Doster AR, Christian JS, Galeota JA, Wills RW, Zimmerman JJ, Osorio FA: Porcine reproductive and respiratory syndrome virus replicates in testicular germ cells, alters spermatogenesis, and induces germ cell death by apoptosis. J Virol 1997, 71:9170-9179.

11. Karniychuk UU, Saha D, Geldhof M, Vanhee M, Cornillie P, Van den Broeck W, Nauwynck HJ: Porcine reproductive and respiratory syndrome virus (PRRSV) causes apoptosis during its replication in fetal implantation sites. Microb Pathog 2011, 51:194-202.
12. Wang G, Song T, Yu Y, Liu Y, Shi W, Wang S, Rong F, Dong J, Liu H, Cai X, Zhou EM: Immune responses in piglets infected with highly pathogenic porcine reproductive and respiratory syndrome virus. Vet Immunol Immunopathol 2011, 142:170-178.

13. He Y, Wang G, Liu Y, Shi W, Han Z, Wu J, Jiang C, Wang S, Hu S, Wen H, et al: Characterization of thymus atrophy in piglets infected with highly pathogenic porcine reproductive and respiratory syndrome virus. Vet Microbiol 2012, 160:455-462.

14. Liu Y, Shi W, Zhou E, Wang S, Hu S, Cai X, Rong F, Wu J, Xu M, Li L: Dynamic changes in inflammatory cytokines in pigs infected with highly pathogenic porcine reproductive and respiratory syndrome virus. Clin Vaccine Immunol 2010, 17:1439-1445.

15. Qiu HJ, Tian ZJ, Tong GZ, Zhou YJ, Ni JQ, Luo YZ, Cai XH: Protective immunity induced by a recombinant pseudorabies virus expressing the GP5 of porcine reproductive and respiratory syndrome virus in piglets. Vet Immunol Immunopathol 2005, 106:309-319.

16. Fenaux M, Halbur PG, Haqshenas G, Royer R, Thomas P, Nawagitgul P, Gill M, Toth TE, Meng XJ: Cloned genomic DNA of type 2 porcine circovirus is infectious when injected directly into the liver and lymph nodes of pigs: characterization of clinical disease, virus distribution, and pathologic lesions. J Virol 2002, 76:541-551.

17. Fenaux M, Opriessnig T, Halbur PG, Meng XJ: Immunogenicity and pathogenicity of chimeric infectious DNA clones of pathogenic porcine circovirus type 2 (PCV2) and nonpathogenic PCV1 in weanling pigs. J Virol 2003, 77:11232-11243.

18. Fenaux M, Opriessnig T, Halbur PG, Elvinger F, Meng XJ: A chimeric porcine circovirus (PCV) with the immunogenic capsid gene of the pathogenic PCV type 2 (PCV2) cloned into the genomic backbone of the nonpathogenic PCV1 induces protective immunity against PCV2 infection in pigs. J Virol 2004, 78:6297-6303.

19. Halbur PG, Paul PS, Frey ML, Landgraf J, Eernisse K, Meng XJ, Lum MA, Andrews JJ, Rathje JA: Comparison of the pathogenicity of two US porcine reproductive and respiratory syndrome virus isolates with that of the Lelystad virus. Vet Pathol 1995, 32:648-660.

20. Sgonc R, Wick G: Methods for the detection of apoptosis. Int Arch Allergy Immunol 1994, 105:327-332.

21. Tong GZ, Zhou YJ, Hao XF, Tian ZJ, An TQ, Qiu HJ: Highly pathogenic porcine reproductive and respiratory syndrome, China. Emerg Infect Dis 2007, 13:1434-1436.

22. Bertin A, Mangenot S, Renouard M, Durand D, Livolant F: Structure and phase diagram of nucleosome core particles aggregated by multivalent cations. Biophys J 2007, 93:3652-3663.

23. Choi C, Chae C: Expression of tumour necrosis factor-alpha is associated with apoptosis in lungs of pigs experimentally infected with porcine reproductive and respiratory syndrome virus. Res Vet Sci 2002, 72:45-49.

24. Suarez P, Diaz-Guerra M, Prieto C, Esteban M, Castro JM, Nieto A, Ortin J: Open reading frame 5 of porcine reproductive and respiratory syndrome virus as a cause of virus-induced apoptosis. J Virol 1996, 70:2876-2882

doi:10.1186/1743-422X-11-2

Cite this article as: Wang et al:: Comparative analysis of apoptotic changes in peripheral immune organs and lungs following experimental infection of piglets with highly pathogenic and classical porcine reproductive and respiratory syndrome virus. Virology Journal 2014 11:2.

\section{Submit your next manuscript to BioMed Central and take full advantage of:}

- Convenient online submission

- Thorough peer review

- No space constraints or color figure charges

- Immediate publication on acceptance

- Inclusion in PubMed, CAS, Scopus and Google Scholar

- Research which is freely available for redistribution 